\title{
CRESCIMENTO PESSOAL, MEDIAÇÃO E SACRIFÍCIO: ITINERÁRIOS SOCIAIS DE ESTUDANTES BENEFICIÁRIOS DO PROUNI
}

\author{
Andrea Bayerl Mongim*
}

RESUMO: Este artigo analisa itinerários sociais de estudantes oriundos de famílias consideradas de classes populares e beneficiários do ProUni. Discute o processo de constituiçáa de significados e de incorporaçáo prática de princípios que concorreram para construçáo e objetivaçáo do projeto de aquisição do título universitário. Tal projeto é construído de forma não naturalizada, efetivando-se pela interação com agentes mediadores, posicionados em quadros institucionais que ultrapassam os limites das redes de relaçóes da família nuclear. A conclusão do curso superior representa a possibilidade de exercer profissão melhor remunerada e valorizada e de incluir-se em grupo de maior prestígio e status.

Palavras-chave: ProUni. Título universitário. Mediação social. Prestígio e status social.

\section{PERSONAL IMPROVEMENT, MEDIATION AND SACRIFICE: SOCIAL ITINERARIES OF PROUNI'S BENEFICIARY STUDENTS}

ABSTRACT: This article analyzes the social itineraries of students from families regarded as belonging to popular classes, who have benefitted from ProUni. It discusses the process of constitution of meanings and the practical incorporation of principles which contributed to the constitution and feasibility of the university degree acquisition project. The project is conceived in a non-naturalized way, implemented through interaction with mediating agents, placed in institutional frameworks that go beyond the limits of the nuclear family relationship network. Completion of a higher education programme represents the possibility of practicing a better paid and more valued profession and of being included in a group that has higher prestige and status.

Keywords: ProUni. University degree. Prestige and social status. Social Mediation.

\footnotetext{
* Universidade Federal do Espírito Santo, Programa de Pós-graduação em Ciências Sociais. Vitória, ES., Brasil. E-mail de contato: ambayerl@hotmail.com.
} 


\section{LA CROISSANCE PERSONNELLE, LA MÉDIATION ET LE DÉVOUEMENT: ITINÉRAIRES SOCIAUX DES ÉTUDIANTS BÉNÉFICIAIRES DU PROUNI}

RÉSUMÉ: Cet article examine des trajectoires sociales des étudiants issus de familles considérées des classes inférieures et bénéficiaires du ProUni. On aborde le processus de constitution de significations et d'incorporation pratique des principes qui ont contribué à la construction et à l'objectivation du projet d'acquérir un diplôme universitaire. Tel projet est construit de manière non naturalisé, en effectuant des relations avec des agents de médiation, insérés dans le système institutionnel, cela dépasse les limites de la relation familiale nucléaire. Le diplôme de l'enseignement supérieur représente la possibilité d'exercer une profession mieux rémunérée et valorisée et de s'insérer dans un groupe où il y a plus de prestige et de statut.

Mots-clés: ProUni. Cours supérieur. Le prestige et le statut social. Médiation Sociale.

\section{Introdução}

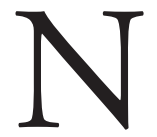

este artigo analiso itinerários sociais de estudantes que, oriundos de famílias consideradas de classes populares, investiram, nos últimos cinco anos, para ingressar em Instituição de Ensino Superior privada, na condição de beneficiários do Programa Universidade para Todos (ProUni). ${ }^{1}$

O estudo incide sobre situação social em que o acesso ao ensino superior se constitui como problemática política. $\mathrm{O}$ aumento da demanda pela incorporação desse nível de ensino é claramente percebido mediante diferentes estratégias construídas, visando ampliar a integração às universidades. A partir dos anos 1990, por todo o país, expandiram-se movimentos sociais referenciados a este objetivo, especialmente pela consolidação de cursos do tipo Pré-Vestibular para Negros e Carentes. Paralelamente e referenciadas pelo debate internacional do movimento negro, que proclama o implemento de açóes afirmativas ${ }^{2}$ para a redução das desigualdades de oportunidades, essas organizaçóes, no Brasil, têm atuado na defesa de políticas que garantam o ingresso no ensino superior, especialmente por meio de programas de reserva de cotas étnico-raciais em universidades públicas.

O designado processo de inclusão no ensino superior, reivindicado por representantes de diferentes movimentos sociais e levado à frente por implementação de recentes políticas de ação afirmativa, vem assumindo contornos polêmicos e instituindo um acalorado debate, tanto no espaço público como no campo acadêmico. 
No que mais interessa para efeito de elaboração deste artigo, enfatizo o quanto o debate público sobre o ProUni vem ganhando espaço nas pautas de análises acadêmicas. Embora ainda incipientes, boa parte dos trabalhos até então produzidos advêm, em geral, de pesquisadores vinculados à universidade pública. Em geral, posicionam-se contrários ao ProUni, comungando do argumento segundo o qual o programa significa uma extensão da política de privatização do ensino superior. Os trabalhos produzidos por Almeida (2006) e Carvalho (2006) são representativos desta perspectiva.

A maior parte dos autores que buscam analisar programas de reserva de cotas nas universidades ou que analisam o ProUni, como uma extensão do projeto de privatização do ensino superior, o fazem com base em pesquisas de caráter documental e bibliográfico. Acabam secundarizando a análise relativa às concepçóes e práticas dos atores envolvidos diretamente no processo, na condição de beneficiários desses programas.

Nesses termos, situando-me em perspectiva antropológica, tomo como proposta analisar os itinerários sociais de estudantes universitários considerados de classes populares e beneficiários do ProUni, privilegiando o processo de constituição de significados e de incorporação prática de princípios constituintes que concorrem para a construção e a objetivação do projeto de aquisição do diploma de curso superior. Destaco, nos itinerários sociais, as interaçóes com agentes de mediação que ultrapassam o sistema de valores da família nuclear e das respectivas redes de relaçóes.

Ao me referir à mediação social, posiciono-me diante da proposta analítica que a concebe contrapondo-se "[...] aos essencialismos e positivismos, aos substantivismos absolutizantes, bem como à dicotomização entre indivíduo e sociedade [...]”. (NEVES, 2008, p.23) Trata-se de uma proposta que:

\begin{abstract}
Alude à representação dialética porque valoriza as representaçóes e as transformaçóes do mundo, a institucionalização, a conciliação, a conformação e o questionamento quanto às regras que legitimam reconhecidas ordens sociais. Implicando, portanto, no reconhecimento dos significados coletivamente produzidos e intercomunicados, a utilidade explicativa do termo mediação funda-se na abertura para compreensão da construção da ordem social. (NEVES, 2008, p. 24)
\end{abstract}

Diante de tal proposta, a mediação social é concebida como processo de intercomunicação entre diferenciados universos sociais, "[...] só alcançáveis se corresponderem a saberes obtidos pelo mediado, isto é, se este se apresenta como sujeito de produção de inerentes novos saberes [...]”. (NEVES, 2008, p. 39) Isto significa que a ação do mediador não se restringe a interligar mundos diferencia- 
dos, pois ele também constrói e, portanto, tenta relativizar as representaçóes dos mundos sociais que pretende interligar e o campo de relações que viabiliza esse modo específico de interligação.

Sob tal perspectiva, a mudança pensada pelo processo de mediação não significa a passagem de um universo de significados a outro. A ação dos mediadores sociais no processo de mudança para a posição de estudantes universitários não é concebida como sendo resultante da imposição da vontade dos primeiros; isto seria destituir esses atores, os estudantes, de voz e vez. É preciso considerar a mediação construída na participação ativa tanto de mediadores quanto de mediados, pois é o entendimento da ação recíproca entre tais atores que conduz à compreensão do "[...] conjunto das forças sociais em jogo, isto é, colocar o ator na história, para se interrogar sobre a produção das situações históricas [...]”. (NEVES, 2008, p. 39)

Do ponto de vista metodológico, busquei me aproximar da perspectiva proposta por Bertaux (1997), optando pela realização de entrevistas do tipo "relato de vida". Considerando que o termo "história de vida" apresenta-se de forma pouco conveniente, uma vez que não distingue a história vivida por uma pessoa e o relato feito por ela, Bertaux (1997) elege por opção epistemológica, da qual compartilho, "relatos de vida" como unidade de análise. Assim o faz compreendendo que o termo se apresenta de forma epistemologicamente mais adequada, uma vez que um relato pessoal somente corresponde a uma aproximação da história objetivamente ou subjetivamente vivida por alguém. Portanto, ao optar pela reconstituição da história de vida de alguém, exclusivamente através do seu próprio relato, o pesquisador somente tem a ilusão de tê-lo feito.

De acordo com o mencionado autor, “[...] o relato de vida resulta de uma forma particular de entrevista, uma entrevista narrativa, ao curso da qual um pesquisador solicita a uma pessoa, denominada sujeito, a contar toda ou parte de sua experiência vivida [...]". (BERTAUX, 1997, p. 6) Defini como "categoria de situação" estudantes, beneficiários do ProUni, residentes em bairros do município de Cariacica/ES que, entre o primeiro semestre do ano de 2005 e o segundo de 2008, ingressaram em Instituição de Ensino Superior (IES) privada, situada em Vitória, capital do estado do Espírito Santo.

\section{Itinerários sociais e mediações subjacentes}

O projeto de ingressar na faculdade e obter um diploma de curso superior é construído ao longo dos itinerários sociais dos estudantes. Todavia, a possibilidade de deslocamento para uma nova posição social só se torna possível, na maioria dos casos, a partir da constituição de redes de apoio e da interação com agentes que operam como mediadores, por estarem situados para além do universo 
da família nuclear. Operacionaliza-se, portanto, pela ação orientada segundo fins almejados, mas incertos, isto é, como projeto desnaturalizado, não evidentemente definido pelas famílias dos estudantes.

Ao analisar casos de "sucesso escolar" nas classes populares, destacando as causas do improvável e contrapondo-se às análises que buscam explicaçóes deterministas para situaçóes heterogêneas, Lahire (2004) propôs uma perspectiva analítica centrada na concepção de interdependência dos fenômenos, mais particularmente no conceito de configuração social, conforme definição de Elias (1994). O autor procurou demonstrar o quanto as singularidades existentes nas configurações familiares são fundamentais para a interpretação desse processo.

Nessa mesma perspectiva muitos outros pesquisadores fundamentaram seus trabalhos. No Brasil, especialmente no campo da sociologia da educação, um bom número de estudos foi produzido procurando demonstrar a importância das configurações familiares para os casos de "longevidade escolar" (VIANA, 2005) nas classes populares. Concebo como inegável a importância da ação dos agentes mediadores presentes nas famílias, especialmente no processo de socialização primária, como edificantes de um projeto de escolarizaçáo bem-sucedido. No entanto, especialmente nas consideradas sociedades complexas, no processo que Berger e Luckmann (2001) chamaram de "socialização secundária", outras redes são tecidas e outras mediações constituídas.

O processo de mudança para a posição de estudantes universitários pressupóe a interação com diferenciados mediadores, posicionados, na maior parte das vezes, em quadros institucionais que ultrapassam os limites das redes de relaçóes da família nuclear. Tal interlocução se dá tanto na elaboração do projeto como em sua execução. Os referidos agentes podem ser mediadores "personalizados", como membros da família extensa, professores, colegas de trabalho, mas também e, muitas vezes, mediadores do tipo "formal-legal". Esses últimos posicionados nas organizaçóes e programas governamentais, como é o caso dos técnicos que atuam no ProUni, ou afiliados a projetos e programas não governamentais, como aqueles que atuam em cursos do tipo Pré-vestibular para Negros e Carentes (PVNC), organizados pelos movimentos sociais, expressóes de um projeto coletivo de ampliar o ingresso na universidade pelas classes populares.

Outros trabalhos também demonstraram, mesmo de forma indireta, as relaçóes que estudantes de classes populares estabelecem com mediadores personalizados ou com aqueles do tipo formal-legal no processo de mudança para a posição de estudantes universitários. Refiro-me aos estudos desenvolvidos por Dauster (2004), Souza e Silva (1999), Teixeira (2003) e Honorato (2004). A primeira autora analisou a entrada e permanência de estudantes beneficiados por uma bolsa social (institucional) de uma universidade não-pública. Honorato (2004), assumindo como propósito discutir as "estratégias coletivas em torno da 
formação universitária”, analisou os itinerários de estudantes que ingressaram na Universidade Federal do Rio de Janeiro, a partir da inserção nos cursos PVNC. Silva (1999) buscou analisar itinerários escolares bem-sucedidos, objetivados por moradores das comunidades da Maré - um dos maiores complexos de favelas do Rio de Janeiro - rumo ao curso superior. Por sua vez, Teixeira (2003) teve a intenção de contribuir para o estudo das relações raciais, através da análise dos itinerários de estudantes e professores negros de uma IES pública, a Universidade Federal Fluminense (RJ). Constatando que o perfil dos seus entrevistados se caracteriza por "[...] indivíduos de origem social mais baixa, que freqüentaram escolas de primeiro e segundo graus de ensino deficiente e que, por alguma razão, conseguem ascender ao ensino superior, considerado de bom nível [...]" (TEIXEIRA, 2003, p. 186), a autora demonstra que a capacidade de estabelecer uma rede de solidariedade e ajuda foi o fator determinante das trajetórias em ascensão.

Embora não tomando os agentes e redes de mediação como perspectiva de análise, posto que adotam objetivos diferentes dos aqui propostos, esses estudos corroboram o argumento por mim desenvolvido, à medida em que consideraram, como fundamentais, na construção e consolidação do projeto de ingresso no ensino superior, as relaçóes que os mencionados estudantes estabeleceram para além do universo familiar.

\section{Escolarização dos filhos como projeto familiar}

Mesmo que não definam até quando estudar e, na grande maioria das vezes, a possibilidade da obtenção de um título universitário não seja vislumbrada, os agentes da família cultivam claramente uma ética da escolarização segundo a qual aos estudos deve se dispensar o máximo de atenção, tornando-o possível, ainda que sob condiçóes pouco favoráveis. Compartilham a concepção de que a educação formal constitui-se no bem maior que os pais podem proporcionar aos filhos. Portanto, os gastos com os estudos devem se sobrepor aos demais bens de consumo. Em muitos casos, os pais destacam o quanto se sacrificaram para manter os filhos estudando. A este respeito, o relato a seguir parece bastante significativo.

Que eu me lembro, meu pai sempre motivou a gente a estudar, nunca disse até quando estudar, se até o segundo grau, eu não me lembro bem ele falando disso, mas sempre falava para estudar. Se precisasse comprar livro, o pouco que ele ganhava ele comprava caderno, o que precisasse (Marcos, aluno do curso de psicologia).

O projeto de escolarização se constitui, na maior parte das vezes, em empreendimento familiar. Tanto o incentivo do pai quanto o da mãe são também 
orientados por um desejo de que os filhos possam realizar um projeto que, eles próprios, embora desejassem, não conseguiram realizar, diante das condições vivenciadas. A escolarização dos filhos constitui-se, assim, numa espécie de "tentar outra vez", retomar, em outras condições, um desejo frustrado.

\section{Universos de mediação social e acesso ao ensino superior}

Como anteriormente destacado, o projeto de ingressar no curso superior constitui-se e objetiva-se, muito especialmente, a partir das interaçóes que se estabelecem com indivíduos ou grupos que operam como mediadores sociais, posicionados nas diferentes redes de sociabilidade constituídas ao longo dos itinerários em questão.

Parte-se da concepção de que o conhecimento do outro deve ser valorizado em toda sua dimensão, uma vez que os agentes institucionais são portadores de posiçóes e conhecimentos concebidos como privilegiados. Em alguns casos, parte desses agentes posicionam-se na própria rede de relaçóes familiares, embora não necessariamente na família nuclear. São primos, tios ou maridos os principais incentivadores e/ou intermediários do projeto.

Fui crescendo, vendo toda empolgaçâo deles. Quando vinham de férias para Vitória, traziam muitos materiais de apresentação de trabalhos, seminários, teatro e coisa e tal. Era tudo muito diferente. Lembro-me que minha prima falava da educação de uma forma empolgante e que ao mesmo tempo eu náo entendia direito do que ela tava [sic] falando. Hoje quando me lembro do discurso dela, já consigo entender do que estava dizendo naquela época. E dessa forma fui acompanhando a graduação deles (Lúcia, aluna do curso de Psicologia).

Não desprezando o apoio pregresso dos agentes familiares que incentivaram e apoiam essa projeção, como o pai ou irmãos mais velhos, é para além dos limites do mundo doméstico que se posicionam os agentes mediadores fundamentais ao projeto de mudança da posição social. São interações constituídas no mundo da escola, do trabalho, mas, também, nas instituiçôes religiosas e no engajamento maior ou menor e da abertura para acesso a recursos diversos, que os desdobramentos dos movimentos sociais populares propiciam. Estes últimos são instituiçóes mediadoras dotadas de um projeto coletivo de mudança.

Em muitos dos itinerários analisados, após conclusão do hoje denominado ensino médio, muitos estudantes ingressam no mundo do trabalho. Em alguns casos, quando o fazem, adiam o projeto de ingresso na faculdade. Em 
outros, é a partir das interaçóes com mediadores posicionados nesse universo que irão constituí-lo, percebendo o curso superior como importante e necessário. Em muitos casos, essa mediação é feita por colegas de trabalho que exercem funçóes especializadas e que possuem formação em nível de terceiro grau. Em geral, percebendo a dedicação e o bom desempenho no trabalho por parte dos estudantes, estimulam-nos a também buscarem uma especialização, apresentando-lhes um outro universo assim factível de projeção de novas posições no futuro. Nesta posiçãa, o diploma de curso superior é percebido como necessário à mobilidade interna em um sistema de funçóes conhecido.

O exemplo de Raquel, aluna do último período do curso de nutriçáo, é bastante significativo dessa abertura de mundo social. Começou a trabalhar na área da saúde, num programa de combate à hipertensão, numa policlínica administrada pela Prefeitura Municipal de Cariacica. Com a conclusão do curso técnico em enfermagem, condição básica para exercer o cargo de Coordenadora de Unidade, realizou processo seletivo interno, sendo aprovada. Percebendo-se em carreira ascendente, com o novo cargo e com o incentivo de médicos com os quais trabalhava, decidiu-se pelo ingresso no curso superior. Quando questionada a respeito das expectativas após conclusão do curso, respondeu:

Como eu já trabalho na Prefeitura de Cariacica, eu vou tentar encontrar alguma coisa relacionada à Nutrição. Porque nas escolas municipais tem nutricionista e eu vou correr atrás desta parte. E pra [sic] mim é mais fácil porque eu trabalho com muitos médicos que atuam em muitos lugares. Inclusive tem um médico que já me falou: eu vou conseguir alguma coisa na área de nutrição para você. Eu achei interessante e vou correr atrás.

Em muitos casos, as interações com os agentes portadores de conhecimento quanto à interseção de universos se estabelecem a partir da ocupação de novas posições em movimentos sociais, mormente movimentos ambientais, religiosos, como é o caso dos grupos de jovens católicos e, com maior frequência, os movimentos com o propósito de ampliar o acesso ao ensino superior por parte das classes populares, como é o caso do PVNC. Seis dos entrevistados prepararam-se para o vestibular através desses cursos.

As interações com agentes mediadores integrados a movimentos sociais são amplas na correspondência dos fatores que incidem na emergência dessas açôes coletivas, propiciando mais amplas alternativas de vislumbrar projetos de ingresso no curso superior. No caso de Wilson, aluno do curso de filosofia, por exemplo, as relaçóes construídas no movimento ambiental o colocaram em contato com um universo social diferente daquele com o qual convivia no seu dia a dia, abrindo caminhos para o projeto de ingressar na faculdade. 
Tem uma associação de Cariacica e Viana chamada Asiarfa [Associação Intermunicipal Ambiental em Defesa do Rio Formate e seus Afluentes] que eu comecei a participar também. Em 2005 eu fui para Brasilia, no II Encontro da Juventude pelo Meio Ambiente. Participei desse encontro por conta desse engajamento politico- ambiental. Também porque meu pai foi militante político, sempre foi PT, ele me levava para as reunióes e eu acho que acabei sofrendo influência disso, né? Ai você conhece coisas novas e você percebe que os vizinhos e os amigos que não estão na faculdade, por exemplo, parece que o mundo deles é pequeno. Então, você vê um monte de coisas novas e quer trazer pra [sic] casa e as pessoas não aceitam e te olham com indiferença.

No caso de Pedro, aluno do curso de Serviço Social, as relaçóes se entreteceram a partir do grupo de jovens da igreja católica.

Eu sempre fiz parte da igreja católica e era integrante do grupo de jovens, me lembro que eu e meus colegas sempre trocávamos informaçôes sobre o que queríamos fazer no segundo grau, ensino médio e depois. Muitos falavam que iam estudar somente o segundo grau, uns diziam que iam fazer curso técnico, tanto que fui incentivado por um colega do grupo da igreja a tentar a prova do Cefetes, na época. Enfim, trocávamos informaçóes sobre curso superior que faríamos depois do curso técnico.

Em dois outros casos, a participação em movimentos sociais, ainda que com objetivos diferentes dos PVNC, e o contato com agentes que se colocaram como mediadores posicionados para além do grupo familiar, foram representativos da abertura para outros universos, isto é, percepçóes e autorizaçóes sociais para construção da expectativa de projeção de uma vida melhor, por onde seria possível crescer.

\section{Crescimento pessoal, valor moral e mobilidade}

Nos itinerários analisados é frequente a concepção de que o curso da vida deve se referenciar pela necessidade de crescer. Embora se constitua numa espécie de princípio orientador da vida, o projeto de crescer é muito comumente concebido de maneira abstrata, muito pouco objetivado. Significativa parte dos relatos parece revelar, porém, que crescer adquire o significado de mudança da posição de subordinação, não objetivando, necessariamente, um grande aumento do capital econômico. A esse respeito Marcos relatou o seguinte: 
Na Telemar eu era ligador, lá a gente se auto-intitulava auxiliar técnico de telecomunicaçôes, mas o título mesmo da função é ligador. A gente trabalhava dentro da central telefônica atendendo às demandas do instalador-reparador que ficava na rua. Era interessante também. Lá eu me identifiquei, o trabalho era interessante, mas não tinha muito para você crescer, o máximo que você podia fazer no trabalho era eu saber o máximo que eu pudesse sobre todo o sistema (Marcos, aluno do curso de psicologia).

Embora pouco objetivado, muito comumente cultiva-se a crença de que o crescimento possa ser alcançado mediante a integração a curso superior, como se pode observar no relato seguinte.

Na época eu não sei se queria fazer administração ou psicologia. Eu não sabia ao certo não. Eu sabia que queria fazer um curso superior, eu queria crescer. (Larissa, aluna do curso de serviço social)

Observa-se que, mesmo que não se saiba qual curso fazer, o importante é ter um diploma universitário. Por conseguinte, o curso superior apresenta-se como condição fundamental para a concretização do projeto de crescer, conforme demonstra, por exemplo, o relato a seguir.

Trabalhei em comércio. Foram 20 anos de comércio. Eu crescia profissionalmente, mas crescia assim: de caixa passava pra [sic] analista de crédito, porque quem não tem o ensino superior não tem muita chance de crescer profissionalmente. Ai foi isso que me motivava também. Eu pensava: não posso ficar toda vida trabalhando no comércio, eu queria crescer. (Larissa, concludente do curso de Serviço Social).

O curso superior parece representar a autorização necessária para o estudante se apresentar como alguém dotado de conhecimentos específicos capazes de tornar possível a mudança da posição de trabalhador subordinado para a de trabalhador especializado e com mais autonomia. Observa-se, nos relatos, que o exercício de funçóes não especializadas, ligadas ao comércio, como de vendedor(a) ou caixa, parece se constituir numa das melhores expressóes desta subordinação. Mais facilmente alcançável com o ensino médio e demonstrando a relatividade do valor atribuído ao trabalhador dotado apenas desse nível de ensino, o acesso inicial a essas funçóes representa mais claramente a posição de onde é preciso sair para ser possível crescer.

Uma vez constituído nas relaçóes estabelecidas com os referenciados mediadores, a consolidação do projeto de ingresso no curso superior esbarra, num primeiro momento, em duas principais condiçóes: a não aprovação nos 
exames vestibulares, impossibilitando o ingresso em uma universidade pública, e a ausência de condiçóes materiais para pagar a mensalidade em uma IES privada. Diante dessas impossibilidades, a bolsa do ProUni é comemorada pelos estudantes como uma grande conquista, como o recurso que faltava para o ingresso no ensino superior.

Porém, se a conquista da bolsa possibilita o ingresso no curso superior, em pouco tempo percebe-se que náo se trata de tarefa simples o cumprimento das exigências necessárias à sua manutenção. Enquanto preparam-se para o Exame Nacional do Ensino Médio (Enem), os estudantes também buscam reunir condições que, somadas à bolsa, permitam-lhes, de fato, estudar. Na maioria dos casos, especialmente por parte daqueles já inseridos no mercado de trabalho, buscam-se construir estratégias para conciliar trabalho e estudo. Entre os que não trabalham, a busca se dirige à construçâo de estratégias que lhes possibilitem possuir algum tipo de ganho financeiro necessário às demais despesas, desde passagens de ônibus até cópias dos textos para estudo.

Nessas circunstâncias, os valores associados à ética do sacrifício orientam o processo de mobilidade e o dignificam. Só parece ser possível o deslocamento de posição social a partir da valorização de um sistema que exige não só dedicação, mas a abstinência relativa a determinadas práticas concebidas como propiciadoras de prazer e bem-estar. É preciso dormir pouco, estudar nos fins de semana, não sendo praticamente possível reservar tempo para o lazer.

Embora tenham analisado o sacrifício com base no estudo minucioso e bem documentado de duas religióes, o hinduísmo e o judaísmo, Mauss e Hubert, ao concluírem o "ensaio sobre a natureza e a função do sacrifício", chamaram a atenção para a importância da dimensão não propriamente religiosa de tal fato social. Argumentam que:

Pudemos ver, ao longo do estudo, quantas crenças e práticas sociais que não são propriamente religiosas se encontram em relação com o sacrifício. Tratamos sucessivamente da questão do contrato, da redenção, do castigo, da dádiva, da abnegação, das ideias relativas à alma e à imortalidade que são ainda a base da moral comum. Isso comprova a importância da noção de sacrifício para a sociologia. (MAUSS; HUBERT, 2005)

Nesse sentido, as práticas representativas de uma ética do sacrifício, por parte dos estudantes, aproximam-se da proposta dos referidos autores ao relacionarem sacrifício e dádiva e explicitarem que:

Em todo sacrifício há um ato de abnegação, pois quem se sacrifica se priva e se dá. Essa abnegaçáo lhe é mesmo frequentemente imposta como um dever. [...] Mas essa abnegaçáo e essa 
submissão não deixam de ter um lado egoísta. Se o que sacrifica dá alguma coisa de si, ele náo se dá; ele se reserva prudentemente. É que se ele dá, é em parte para receber. O sacrifício se apresenta, então, sob um duplo aspecto. E um ato útil e uma obrigação. $\mathrm{O}$ desinteresse se mescla ao interesse. Por isso ele foi frequentemente concebido sob a forma de um contrato. (MAUSS; HUBERT, 2005)

No caso em questão, a conciliação entre o caráter obrigatório e utilitário do sacrifício parece clara. É necessário e obrigatório abnegar-se e privar-se para ser recompensado, pois, da mesma forma que é dando que se recebe, é também se sacrificando que se é recompensado. Postula-se a crença numa obrigatória recompensa diante do ato de dar-se em sacrifício, nos termos da moral da dádiva pautada nas obrigaçóes de dar-receber e retribuir. Se me dou em sacrifico, receberei obrigatoriamente uma recompensa. Fazer um curso superior, deslocando-se para uma posição social supostamente de maior prestígio, constitui-se, para estes estudantes, a grande recompensa.

\section{Os dilemas da mobilidade social}

O processo de mobilidade é construído entre muitos dilemas e constrangimentos. A inserção num novo universo de significados traz à tona sentimentos e sentidos diversos reveladores, muitas vezes, do dilema inerente à condição de ser universitário e bolsista. Mesmo que o outro não seja objetivamente definido, há, por parte da maioria dos estudantes, a sensação de que a vida transita entre dois mundos, em universos simbólicos diferentes. Por isso, ao mesmo tempo em que o acesso à nova posição é comemorado, a percepção da alteridade pode se apresentar como um desafio.

Apesar de, na maior parte das vezes, os estudantes tenderem, por efeitos de posição, secundarizar as dificuldades no estabelecimento de relaçóes com o abstratamente chamado "outro", parte deles revelou sentimentos de autoexclusão e de discriminação, evidenciando a dificuldade de convívio com as diferenças, neste caso, também expressa na desigualdade social.

Dauster (2004), ao analisar as relaçôes entre estudantes integrantes do sistema de categorias denominadas por seus entrevistados de "bolsistas" e "elite", no universo de uma IES não pública da zona sul do Rio de Janeiro, o faz a partir das reflexóes de Elias e Scotson (2000) a respeito dos "estabelecidos" e os "outsiders". Estas categorias, de caráter relacional, são discutidas pelos mencionados autores em uma etnografia das relaçóes de poder na comunidade de Winston Parva (nome fictício), próxima de Leicester, Inglaterra, localidade demarcada pela 
existência de um grupo de moradores antigos da "aldeia", os estabelecidos, que se colocavam como pessoas de "valor humano mais elevado" que o dos moradores do "loteamento" construído em época mais recente, os outsiders, estigmatizados pelos primeiros.

Mesmo considerando não ser produtivo radicalizar a analogia que propóe, Dauster procura demonstrar que os integrantes das categorias "bolsistas" e "elites" convivem em relaçôes de interdependência tensa e desigual, que tanto separam quanto unem, tais quais os "estabelecidos" e os "outsiders". Segundo a autora, "[...] as distinções entre as duas categorias são percebidas em função de relações de evitação e exclusão, em processos de estigmatização e rotulação [...]”. (DAUSTER, 2000, p. 3) Observa ainda que:

Nas queixas dos integrantes dos setores populares em relação a colegas de outros segmentos economicamente privilegiados, percebe-se que a chegada de seus membros à universidade particular é sentida como ameaça ao estilo de vida da universidade e à sua "qualidade", embora o que se entende por qualidade não esteja definido em nenhum momento. (DAUSTER, 2000, p. 4)

As análises de Elias e Scotson apontam ser graças a um maior potencial de coesão que os antigos residentes de Winston Parva, os "estabelecidos", conseguiram reservar para as pessoas de seu tipo os cargos importantes das organizaçóes locais, como o conselho, a escola ou o clube, e deles excluir firmemente os moradores de outras áreas, aos quais, como grupo, faltava coesão. A exclusão e a estigmatização dos outsiders pelo grupo estabelecido constituíam-se em armas poderosas para que este último preservasse sua identidade e afirmasse sua superioridade, mantendo os outros firmemente em seu lugar.

No caso que analiso, não se faz adequado se referir a um grupo já estabelecido na faculdade quando da chegada dos estudantes bolsistas. Também não se observa nenhum grande potencial de coesão e montagem de estratégias visando à ocupação de cargos que confiram poder, por parte de um grupo de possíveis estabelecidos. Desde o início de suas atividades acadêmicas, a faculdade conta com a presença em seu corpo discente de alunos beneficiários de um programa institucional de bolsas. Também é grande a presença, sobretudo em alguns cursos, de alunos que, embora não bolsistas, são oriundos de famílias de baixa renda. De fato, não é possível se referir a não bolsistas ou a bolsistas como grupo, pelo menos no sentido sociológico atribuído ao termo.

A existência de percepçóes e atitudes discriminatórias confirma práticas mais isoladas, não se constituindo em uma estratégia de um grupo coeso, caracterizado por sentimento de pertencimento e formulador de estratégias de controle social e manutenção de poder. Portanto, se os que discriminam compartilham da 
percepção de fazerem parte de algum grupo de "valor humano mais elevado", tal percepção parece assentada em relações sociais estabelecidas para além dos muros da faculdade, amparadas em um sistema social que se estrutura de forma hierárquica e excludente.

Diante do inicial sentimento de discriminação e autoexclusão, os estudantes bolsistas, aos poucos, vão construindo percepçóes orientadoras de estratégias de diferenciação. Imbuídos da crença de prevalecer no quadro institucional de um sistema meritocrático, pautado no alcance de resultados acadêmicos satisfatórios, esforçam-se para torná-los evidentes, conquistando a almejada posição de reconhecimento e aceitação por parte do outro.

Se a inserção num outro universo, o da faculdade, apresenta-se como um desafio, também o é continuar pertencendo ao universo social de origem. Ao mesmo tempo em que se autopercebem e são percebidos, por familiares e amigos, como indivíduos detentores de qualidades especiais, acabam, muitas vezes, assumindo posição que desqualifica o universo social de origem como um mundo pequeno, do qual náo parece mais interessante participar.

Por essa via, a posição de viver no limiar entre dois universos sociais distintos pode representar, ao mesmo tempo, satisfação pelos desafios superados, como também certo sentimento de solidão decorrente de uma ruptura com o universo familiar ou dos amigos. O sentido do pertencimento passa a constituir-se por muitas tensões e constrangimentos. Nesses termos, o processo de mobilidade assume significados expressivos dos prazeres da conquista, mas também tradutores de dores e sofrimentos.

\section{Conclusão}

A condição de estudante bolsista imprime desafios às inter-relações na nova posição e também traz à tona dificuldades de outra ordem. Torna-se muito evidente que a bolsa, por si só, não garante as necessidades intrínsecas à permanência e conclusão do curso superior, pois, além de ser preciso satisfazer os critérios de competência exigidos para a sua manutenção, é também necessário dispor de tempo e de outro tipo de recurso para financiar os demais gastos com a faculdade.

Os valores que orientam a ética do sacrifício se fazem presentes, em muitos casos, dentro de um quadro de alternativas referenciadoras de uma situação de risco. Para alguns entrevistados aliar trabalho e estudo representava o risco de perder a bolsa, uma vez que precisavam garantir rendimento satisfatório para sua manutenção. Em outros casos, a alternativa é deixar o emprego, impondo-se o sacrifício de abster-se de determinados consumos, não mais possíveis sem o salário mensal. A posição inicial de estudante-trabalhador é transformada, durante o cur- 
so, para a de apenas estudante. Isto quando percebem a impossibilidade de obter resultados satisfatórios na faculdade, tendo que também trabalhar. Em um dos casos a alternativa foi negociar uma demissáo, de um emprego considerado como uma grande conquista, podendo contar com os recursos do Fundo de Garantia por Tempo de Serviço.

Essas condiçóes vão configurando um campo de possibilidades representativas da importância do diploma do curso superior para os estudantes. Não é fácil obtê-lo, mas tal obtenção é tão importante que deve se sobrepor a qualquer outra exigência.

Diante de tais condições e, dotados da autopercepção de que estão construindo trajetória ascendente, cultivam a crença de que superar as dificuldades e permanecer estudando dependem da capacidade individual de se colocar em sacrifício.

Por essa via, ingresso e permanência na faculdade não são concebidos como processos que devam resultar da mobilizaçáo coletiva mais ampla, como uma bandeira política a ser empenhada. Constrói-se a crença na possibilidade da permanência e da conclusão do curso superior como uma vitória pessoal, com a certeza de que os compromissos pautados nas relaçóes de dar, receber e retribuir, tradutores da moral da dádiva (MAUSS, 1974) estão sendo cumpridos.

Percebendo-se em ascensão social e cultivando o princípio segundo o qual o percurso da vida deve se referenciar pela permanente necessidade de crescer, ou seja, pela expansão de si, pela autorização própria a se expressarem em público e pela minimização dos constrangimentos em diversos planos (a certos recursos materiais de serviços, por exemplo), os estudantes concebem o curso superior como a grande possibilidade de mudança no plano individual. Desse deslocamento social, alguns se atribuem uma posição de liderança no sentido de propiciar aos familiares e vizinhos as mesmas oportunidades conquistadas ou facilitadas por outrem. Essa atribuição nem sempre corresponde ao desejo social dos demais, razão pela qual muitos deles passam a se sentir estranhos no seu ambiente. Enfim, crescer (tout court) ou crescer na vida sinalizam uma abertura para o mundo, destacando a abertura em si, sem, necessariamente, um ponto de chegada pré-definido. Mais precisamente, expressam a virtude que cria o passaporte necessário à conquista de uma posição de maior prestígio social, adquirindo, no sentido mais restrito, o significado de uma vitória pessoal. E, por isso mesmo, a distinção social que só é de fato reconhecida se apontar para as possibilidades e os quereres dos outros, isto é: crescer é necessário e possível.

Imbuídos dessa crença e por um processo de reprodução agonística do crescimento, os entrevistados manifestam um forte desejo de realizar um curso de pós-graduação. $\mathrm{Na}$ maioria, eles se referem a um curso de especialização Lato Sensu, mas também manifestam o desejo de cursar o mestrado e doutorado. Ad- 
quirir o grau de pós-graduado parece se constituir em importante estratégia para consolidação do passaporte adquirido com o curso superior.

Nesses termos, obter o diploma de ensino superior, realizar uma pós-graduação e inserir-se no mercado de trabalho de forma melhor qualificada e socialmente valorizada colocam-se como formas objetivas do desejo de crescer, princípio orientador da vida. Embora de início pouco objetivado, ele é melhor avaliado a posteriori, configurando de certa maneira um ethos coletivo ou familiar, demonstrado em diversos casos em que esse desejo reafirma e mapeia significados de mudança de posição de subordinação e alcance de maior prestígio e status social.

Conforme definiu Bourdieu (1998, p. 16), “[...] os grupos de status impóem aos que neles desejam participar, além de modelos de comportamentos, modelos da modalidade dos comportamentos, ou seja, regras convencionais que definem a maneira justa de executar os modelos [...]". Esses grupos, portanto, se distinguem não pela maneira de ter bens, mas de usar esses bens.

Em uma sociedade como a brasileira, tâo operada por princípios de hierarquização e exclusão, o título universitário, bem como os seus mencionados desdobramentos, especialmente a grande possibilidade de pertencimento a um grupo de status em que se acredita, seja possível ter voz e vez, é delinear ou vislumbrar expectativas de se igualar àqueles que se posicionam nos concebidos patamares mais elevados dessa hierarquia.

\section{Notas}

1. O Programa Universidade para Todos (ProUni) foi instituído em 2004, pelo governo federal, através de decreto-lei, destinando bolsas integrais e parciais (50\%) a estudantes considerados de "baixa renda", em Instituiçóes de Ensino Superior privadas.

2. Por políticas de ação afirmativa entende-se "[...] medidas especiais e temporárias, tomadas pelo Estado e/ou pela iniciativa privada, espontânea ou compulsoriamente, com o objetivo de eliminar desigualdades historicamente acumuladas, [...] de garantir a igualdade de oportunidade e tratamento, bem como compensar perdas provocadas pela discriminação e marginalizaçáo, por motivos raciais, étnicos, religiosos, de gênero e outros [...]”. (MINISTÉRIO DA JUSTIÇA, 1996).

\section{Referências}

ALMEIDA, S. C. de. O avanço da privatizaçáo na educaçáo brasileira: o ProUni como uma nova estratégia para a transferência de recursos públicos para o setor privado. 2006. Dissertação (Mestrado em Educação) - Programa de Pós-Graduação em Educação, Universidade Federal Fluminense, Niterói, 2006.

BERGER, P. L.; LUCKMAN, T. A construção social da realidade. 22a ed. Petrópolis: Vozes, 2001. 
BERTAUX, D. Les récits de vie: perspectives ethnosociologiques. Paris: Nathan, 1997.

BOURDIEU, P. A economia das trocas simbólicas. São Paulo: Perspectiva, 1998.

BRASIL. Ministério das Relaçôes Exteriores e Ministério da Justiça. Décimo Relatório Periódico Relativo à Convenção Internacional Sobre a Eliminação de Todas as Formas de Discriminação Racial. Brasília: 1996. [GTI População Negra. p. 10].

CARVALHO, C. H. O ProUni no Governo Lula e o jogo político em torno do acesso ao ensino superior. Educ. Soc., v. 27, n. 96, p. 979-1000, Campinas, 2006.

DAUSTER, T. Uma revoluçáo silenciosa: notas sobre o ingresso de setores de baixa renda na universidade. In: CONGRESSO LUSO-AFRO-BRASILEIRO DE CIÊNCIAS SOCIAIS. 8., 2004, Coimbra. Anais... Coimbra: CES, 2004. Disponível em <www.ces.uc.pt/ lab2004/pdfs/TaniaDauster.pdf >. Acesso em: 30 de março de 2014.

ELIAS, N. O processo civilizador. Rio de Janeiro: Jorge Zahar, 1994.

ELIAS, N.; SCOTSON, J. L. Os estabelecidos e os outsiders. Rio de Janeiro: Jorge Zahar, 2000.

HONORATO, G. de S. Estratégias coletivas em torno da formaçáo universitária: Status, igualdade e mobilidade entre desfavorecidos. 2005. Dissertação (Mestrado em Sociologia) - Universidade Federal do Rio de Janeiro, Instituto de Filosofia e Ciências Sociais, Rio de Janeiro, 2005.

LAHIRE, B. Sucesso escolar nos meios populares: as razóes do improvável. São Paulo: Ática, 2004

MAUSS, M. Ensaio sobre a dádiva: formas e razão da troca nas sociedades arcaicas. In: . Sociologia e Antropologia. v. 2. São Paulo: EDUSP, 1974.

MAUSS, M.; HUBERT, H. Sobre o sacrifício. São Paulo: Cosac Naify, 2005.

NEVES, D. P. (Org.). Mediação social e mediadores políticos. In: . Desenvolvimento social e mediadores políticos. Porto Alegre: Editora da UFRGS, 2008, p. 21-44.

SOUZA e SILVA, J. Por que uns e não outros? Caminhada de estudantes da Maré para a universidade. 1999. Tese (Doutorado em Educação). Faculdade de Educação, PUC-RJ, Rio de Janeiro, 1999.

TEIXEIRA, M. P. Negros na universidade: Identidade e trajetórias de ascensão social no Rio de Janeiro. Rio de Janeiro: Pallas, 2003.

VIANA, M. B. As práticas socializadoras familiares como lócus de constituição de disposiçóes facilitadoras de longevidade escolar em meios populares. Educ. Soc., Campinas, v. 26, n. 90, p. 107-125, jan./abr. 2005.

Recebido em 20 de fevereiro de 2015.

Aprovado em 31 de julho de 2015.

DOI: http://dx.doi.org/10.1590/ES0101-73302015146226 